\title{
A small outbreak of Legionnaires' disease in a cargo ship under repair
}

\author{
J.A. Caylà*, R. Maldonado*, J. González", T. Pellicer", D. Ferrer ", C. Pelaz ${ }^{+}$, J. Gracia ${ }^{\S}$, \\ B. Baladrón ${ }^{+}$, A. Plaséncia ${ }^{f}$, Legionellosis study group
}

A small outbreak of Legionnaires' disease in a cargo ship under repair. J.A. Caylà, $R$. Maldonado, J. González, T. Pellicer, D. Ferrer, C. Pelaz, J. Gracia, B. Baladrón, A. Plaséncia, Legionellosis study group. (C) ERS Journals Ltd 2001.

ABSTRACT: It was reported that two mechanics working on a cargo ship under repair in the port of Barcelona had died after having fever.

An investigation was made into the possibility of any additional cases and the presence of Legionella pneumophila in the ship they were repairing and in their hotel. The contaminated water system was treated with sodium hypochlorite.

Both patients died after having been repeatedly diagnosed as having influenza. The two cases occurred among those who had been working with the pump of the ship's water system, while no cases were observed among the other workers $(p=0.02)$. Various serogroups of $L$. pneumophila were isolated from the ship's water pump and distribution system. However, organism of serogroup 1, subgroup Pontiac (Knoxville) were identified with identical deoxyribonucleic acid (DNA) patterns in the lung tissue of one patient and in the cooling water circuit valve of the ship's water pump. The first postintervention control water samples showed no further growth of legionella, but serogrups 4 and 8 were identified 8 months later.

This legionellosis outbreak, although small, was highly lethal, probably due to the high levels of bacteria to which the patients were exposed and also because of the failure of correct diagnosis. International recommendations on prevention and control of legionellosis, which include ships under repair, are required.

Eur Respir J 2001; 17: 1322-1327.

\author{
*Servei d'Epidemiologia, Institut \\ Municipal de Salut Pública, "\#ervei de \\ Microbiologia IDIBAPS, Hospital \\ Clínic, "Laboratori Municipal, Institut \\ Municipal de Salut Pública, ${ }^{+}$Servicio \\ de Bacteriología, Centro Nacional de \\ Microbiología, Instituto de Salud \\ Carlos III, Majadahonda, Madrid, \\ Spain, ${ }^{\S}$ Servei d'Anàlisi i Vigilància \\ Ambiental, Ajuntament de Barcelona \\ and Institut Municipal de Salut Púb- \\ lica, Barcelona, Spain.
}

Correspondence: J.A. Caylà, Servei d'Epidemiologia, Institut Municipal de Salut Pública, P1. Lesseps, 1, 08023 Barcelona.

Fax: 34932182275

Keywords: Legionnaires' disease outbreak

ship

Received: May 242000

Accepted after revision January 52001
The majority of legionellosis cases occur sporadically, and the transmission mechanism is never identified. In contrast, when the disease occurs in the form of an outbreak, this has been related to aerosol producing apparatus (cooling towers, whirlpool spa installations [1-3]), with potable water converted to aerosol in showers and taps [4], and even with public works [5].

The doctor of a shipping company reported the death of two mechanics who had been working on a cargo ship moored in the port of Barcelona. They were part of a team of 11 individuals transferred from Cádiz to Barcelona specifically for this purpose. They were all staying in the same hotel and went to the ship each day, where they were engaged in carrying out a variety of repairs. The aim of the present study was to investigate the cause and extent of a possible disease outbreak, to implement control measures, and to assess their effectiveness.

\section{Materials and methods}

\section{Clinical epidemiological study}

The two deaths were reported to the Barcelona Municipal Institute of Health on February 1, 1999.
An investigation was immediately organized and an epidemiological enquiry initiated. The pertinent courtrooms and toxicological institutes were contacted to obtain the autopsy reports, along with samples of tissue and urine for analysis. The enquiry included interrogation and medical examination of the nine colleagues of the two deceased patients, and of the 21 members of the ship's crew, as well as a review of the available clinical and radiological data on the deceased. The doctors who had attended to them were also interrogated. Based on the clinical and epidemiological information obtained, the enquiry was oriented towards a possible outbreak of pneumonia by Legionella pneumophila. An epidemiological questionnaire was administered to the group of mechanics, identifying the hotel rooms in which they had been staying, and the areas of the ship in which they had been working. Similarly, a check was made to determine if there were cases among workers from other firms who were also involved in repair tasks in the ship. Cases of legionellosis were considered to be confirmed if they had fever and evidence of infection by $L$. pneumophila (isolated in respiratory secretions or lung tissue, detection of L. pneumophila serogroup 1 in urine by immunoassay, or demonstration of seroconversion [6]). 


\section{Environmental study}

Sampling. The choice of sampling points was based on the preliminary results of the epidemiological study, and inspection of installations both in the ship and the hotel. Critical points identified in the ship were the fresh water cooling system circuit and associated pumps, and in the hotel, the showers, hot and cold water taps and hot water accumulators. Samples were taken from all such points in order to check for the presence of $L$. pneumophila (February 3-4, 1999, in the hotel and ship, respectively). In the ship, samples were also taken from the taps and shower of a toilet located near to where the mechanics were working. In a second phase, following detection of L. pneumophila in certain areas of the ship, further samples were taken from a variety of locations. From all sampling points, $2 \mathrm{~L}$ of water were collected in sterile containers. Smear samples were also taken with swabs from the taps and showers. Samples were stored at $4{ }^{\circ} \mathrm{C}$ and laboratory processing initiated within $2 \mathrm{~h}$.

Microbiological procedures. The water samples were concentrated 100 times by filtration through a sterile cellulose ester membrane, with pores of $0.22 \mu \mathrm{m}$ (GS, Millipore, Ireland, UK) followed by resuspension of the membrane in $10-20 \mathrm{~mL}$ of the analysed water. The concentrated samples were divided into 3 aliquots. In order to decontaminate them, the first aliquot was subjected to heat treatment $\left(50^{\circ} \mathrm{C}\right.$ for $\left.30 \mathrm{~min}\right)$, and the second to acid treatment ( $\mathrm{pH} 2.2$ ). The third aliquot was processed directly for culture. A volume of $0.1 \mathrm{~mL}$ of each aliquot was plated on Modified Wadowsky Yee (MWY) agar (Oxoid Limited, Basingstoke, Hampshire, UK). The swabs were plated directly on MWY agar. Cultures were incubated at $35 \pm 1{ }^{\circ} \mathrm{C}$ for 15 days, and inspected every 3 days. Identification of L. pneumophila isolates was based on colony characteristics, Gram staining, hypurate hydrolysis, no culture growth on blood agar and L-cysteine deficient buffered charcoal yeast extract agar supplemented with alpha-ketaglutarate (BCYE $\alpha$ ), and by means of direct fluorescence with monoclonal antibodies (Monofluo, Sanofi Diagnostics Pasteur, Marnes la Coquette, France).

\section{Clinical laboratory study}

Samples obtained. Intravesical urine, serum and post mortem biopsies of lung, spleen and liver tissue were obtained from patient A. On the day of admission to hospital, two blood cultures were performed and serum obtained for serological studies in patient B. Post mortem biopsies were obtained from both lungs, spleen and liver. From the nine other mechanics, urine samples were collected 10 days after the clinical study of patient A, and paired serum samples separated by 5 weeks were also collected. Each of the 21 members of the ship's crew provided 1 serum sample 5 weeks after the start of the outbreak.

Microbiological procedures. Tissue samples were cultivated in conventional enriched media, as well as in Sabouraud media following the recommended methods. BCYE $\alpha$ culture medium with and without antibiotic supplements were used for the detection of L. pneumophila (BBL-Becton Dickinson, Meylan Cedex, France). Urine samples were concentrated (Urifil 10 concentrator, Millipore, Molsheim, France) and analysed by an immunoassay technique capable of detecting the presence of L. pneumophila serogroup 1 antigen (Binax, Portland, Maine, USA). Antibodies to $L$. pneumophila serogroups $1-6$ (total immunoglobulin (Ig)) in serum were detected by indirect immunofluorescence. The presence of antibodies to Chlamydia pneumoniae (IgM, IgG), Coxiella burnetii, (IgG, IgM) and Chlamydia psittaci (IgG) was also investigated by indirect immunofluorescence, and for Mycoplasma pneumoniae (IgG) by complement fixation.

Typing of Legionella pneumophila strains. The identification of isolates at species and subgroup level, and characterization of isolates identified as L. pneumophila serogroup 1 were performed using the International Panel of monoclonal antibodies [7]. Amplified fragment length polymorphism (AFLP) was applied to isolates typed as L. pneumophila serogroup 1 subgroup Pontiac (Knoxville) by digestion of chromosomal deoxyribonucleic acid (DNA) with PstI and subsequent amplification following the method described by VALSANGIACOMO et al. [8] and modified by FRY et al. [9]. The gel of amplified DNA fragments was stained with etidium bromide (BrEt) and photographed with a Polaroid camera.

Histological procedures. A fragment of each tissue sample was embedded in paraffin and sections cut for staining by haematoxylin-eosin, Gram and WarthinSterry methods.

\section{Control measures}

The first control measures taken were closure of the hotel room which the deceased mechanics had shared and prohibition of work in the area of the ship where they had been working until results of the environmental samples taken were known. Subsequently, when it was known that samples from the ship were positive, further locations in the ship were analysed. On March 1, 1999, water was treated with sodium hypochlorite in a concentration of $1.25 \mathrm{~g} \cdot \mathrm{mL}^{-1}$ and $557 \mathrm{~g}$ of active chlorine. This treatment was carried out in the cooling water circuits, sanitary water circuits, and associated taps and shower heads. Twenty days after the sodium hypochlorite treatment, a second set of samples was obtained from the same locations sampled previously. Eight months later, a new set of samples was obtained from the water pump area. Effectiveness of the treatment was based on negativity of samples from the ship.

\section{Statistical analysis}

Fisher's exact test was used to assess association between qualitative variables. 


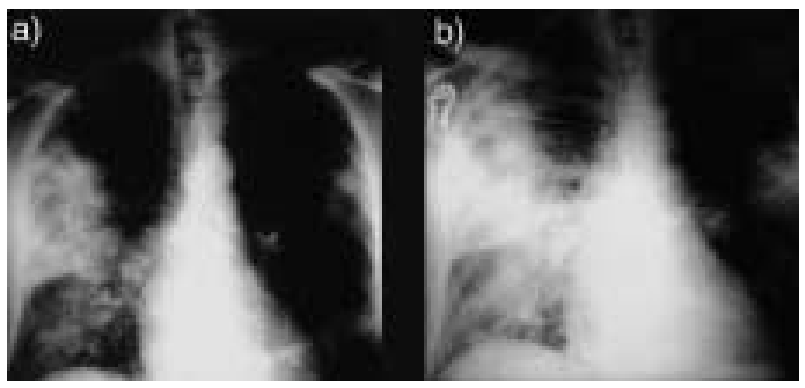

Fig. 1. - Chest radiographs showing a) bilateral alveolar shadowing and $b$ ) progression of infiltrates the following day.

\section{Results}

On January 17, 199911 mechanics from Cádiz travelled to Barcelona to repair a Tunisian cargo ship. The ship was of medium tonnage, and for economic reasons, it had been lying inactive in Tunisia for $2 \mathrm{yrs}$. All the mechanics stayed in the same hotel.

On January 22, 1999 two of these workers began to have fever accompanied by shivering, muscular pain, and diarrhoea, they were repeatedly diagnosed as having influenza, and received symptomatic treatment as outpatients. Patient A was 33-yrs-old, had no relevant pathological history and smoked 20 cigarettes'day ${ }^{-1}$. Patient B was 53-yrs-old, also had no relevant pathological history, and was a moderate smoker and drinker. Patient A returned to Cádiz by train on January 27, 1999, (a journey of some $15-16 \mathrm{~h}$ ) and died in his sleep on the train. The other left for Huesca, where he consulted a doctor on the January 28, 1999. He was diagnosed as having pneumonia, based on clinical and radiological examination, and antibiotic treatment was prescribed. His condition worsened in the following hours and he was admitted to hospital on January 29, 1999 dying $2 \mathrm{~h}$ later. Chest radiographs from the previous day showed bilateral alveolar shadowing, and the hospital records noted progression of infiltrates (fig. 1). The two deceased mechanics shared the same hotel room and both worked with the ship's water pump. As a precaution, their hotel room was closed and work in the area of the ship where they had worked was prohibited.

L. pneumophila serogroup 1 antigen was detected in the urine sample of Patient A. All cultures from the histological samples (liver, lung and spleen) studied were negative after incubation for 15 days. No antibodies were detected by any of the serological techniques applied. The pathology report mentioned marked autolysis with intra-alveolar exudate compatible with bronchopneumonia. A moderate number of colony forming units (cfu) of L. pneumophila serogroup 1 were isolated from the lung tissue sample of Patient B. No micro-organisms were isolated in any of the other biopsies. All antibody detection techniques yielded negative results. The pathology report on the patient's lung concluded that he had acute bronchopneumonia with haemorrhagic foci affecting the majority of the lung parenchyma studied. Among the 21 members of the ship's crew only one had influenza around the same time as the cases were detected. Blood samples were obtained from all of them to test for antibodies, no significant titres were found for any of the pathogens studied. Among the nine other mechanics, neither seroconversion nor raised levels of antibodies to $L$. pneumophila serogroups 1-6 were observed. Considering crew and mechanics together, out of the five who worked with the water pump, only the two cases of L. pneumophila infection were found and no case among the remaining 27. Similarly, no cases were detected among the 95 workers of nine other companies who had also worked on the ship $(\mathrm{p}=0.004)$.

With respect to the environmental study, on February 10, 1999 it was reported that the hotel samples were negative for L. pneumophila. In contrast, positive cultures were obtained from 4 of the 10 samples taken on the ship (table 1). On February 26, 1999 the other locations in the ship were analysed, legionella being isolated in 6 of the 20 samples taken (table 1). Strains of L. pneumophila serogroup 1 isolated from the lung tissue of Patient B and from the main valve of the ship's cooling water circuit

Table 1.-Distribution of ship sampling points where Legionella pneumophila was isolated, and postintervention result*

\begin{tabular}{|c|c|c|c|c|c|}
\hline \multirow[t]{2}{*}{ Location sampled } & \multirow[t]{2}{*}{ Sample type } & \multicolumn{4}{|c|}{ Results, by date of sampling } \\
\hline & & $4.2 .99^{\#}$ & $26.2 .99^{\bullet}$ & 22.3.99 & 16.4.99 \\
\hline \multirow[t]{2}{*}{ Cooling circuit purge value } & Swab & L. $1 ;$ L. 8,10 & \multirow{2}{*}{\multicolumn{3}{|c|}{$(-)$}} \\
\hline & Water & L. 8,10 & & & \\
\hline Fresh water pump (cooling circuit) & Water & L. 8,10 & & $(-)$ & \\
\hline Mechanics' shower & Water & L.8 & & $(-)$ & \\
\hline Shower, 2nd officer's cabin & Water & & L. 8,10 & $(-)$ & \\
\hline Kitchen (left sink hot water tap) & Water & & L. 8,10 & $(-)$ & \\
\hline \multirow[t]{4}{*}{ Office-diningroom (left sink hot water tap) } & Water & & L.10 & $(-)$ & \\
\hline & & & L. $4,8,10$ & & \\
\hline & & & L. 8,10 & & \\
\hline & Swab & & L.10 & & \\
\hline Toilet, chief engineer (cold water tap) & Water & & L. 10,8 & $(-)$ & \\
\hline Shower, chief engineer (two sampling points) & Water & & L. 10,8 & $(+)$ & $(-)$ \\
\hline
\end{tabular}

*: Intervention was carried out on March 1, 1999; ${ }^{\#}$ : 4.22.99: samples from a further 6 points were negative; ${ }^{\oplus}: 26.2 .99$ : samples from a further 14 points were negative; L.1: L. pneumophila serogroup 1 Pontiac, Knoxville. L.4,8,10: L. pneumophila serogroup $4,8,10$. 
pump (fig. 2) corresponded to the Pontiac subgroup (Knoxville). Application of AFLP as the molecular typing method demonstrated that the two strains had identical DNA patterns (fig. 3).

The first control water sampling carried out after treatment with sodium hypochlorite (i.e. 20 days later) still isolated L. pneumophila in one location (table 1). The offending shower head was replaced and a subsequent negative control sample demonstrated the effectiveness of this measure. In the second control samples (i.e. 8 months later), L. pneumophila serogroup 4 and 8 were identified.

\section{Discussion}

Most cases of legionellosis occur sporadically and are not associated with a specific source of infection or with outbreaks. Such sporadic cases have a low rate of declaration to health authorities (in the USA it is estimated that only some $5 \%$ of cases are notified [10]), whereas outbreaks usually have an important media impact. The form of transmission most widely recognized is by aerosol from contaminated sources of water, such as cooling towers, evaporation condensers, whirlpool spa installations, showers, decorative fountains and respiratory therapy equipment [10]. Several outbreaks of legionellosis have been reported in closed communities such as hospitals and hotel [11] of the tourist destinations, Spain is the country with the most cases declared. Outbreaks have also been detected in open communities [12-14], such as that which occurred in 1996, the largest outbreak ever reported in Europe, with $>200$ people affected by L. pneumophila serogroup 1 subgroup Pontiac [15].

L. pneumophila is isolated relatively frequently from ship's water installations, where $>100$ cases have been detected, almost all being cruise ships [16]. However, the first outbreak in cruise ship passengers to demonstrate the source of infection has only recently been reported $[13,17]$, this affected 50

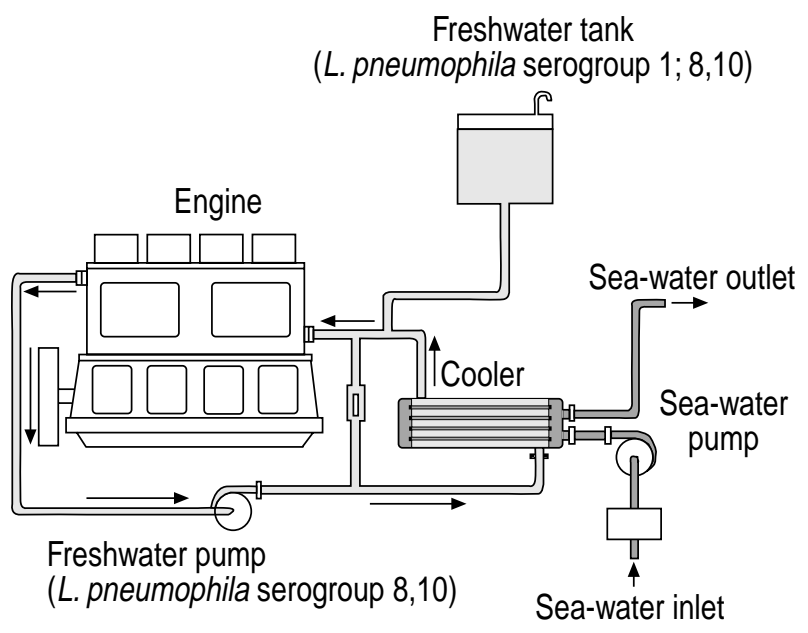

Fig. 2. - Water cooling circuit of the engine including the parts where the positive cultures were found (this circuit is independent of the main water system of the cargo ship). : open circuit (seawater); $\square$ : closed circuit (freshwater).

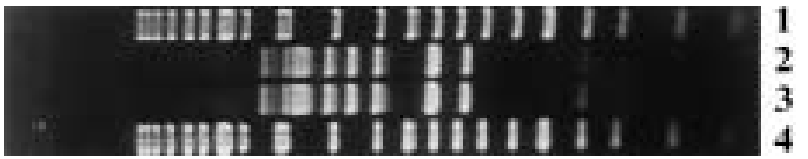

Fig. 3. - Amplified fragment length polymorphism gel. Lanes 1 (on the left) and 4 (on the right) contain the molecular weight marker (100-10,000 pairs of bases, Ladder Mix, MBI Frementas). Lane 2 corresponds to the clinical strain of Patient B, lane 3 the environmental strain from the ship, both are L. pneumophila serogroup 1, Pontiac (Knoxville).

passengers who travelled in the same ship at different times. The source of infection was located in a whirlpool spa installation. Subsequently, three other outbreaks in cruise ships, with the origin of the microorganisms being demonstrated, have been reported [10]. The cases described in the present outbreak are the first to be reported involving a cargo ship.

This outbreak was surprisingly lethal. This could have been influenced by the following. 1) The higher virulence of some Legionella strains. Worldwide, 60 serogroups are known, of which only 14 belong to L. pneumophila. However, most cases of infection are produced by serogroups $1-6$, and by $L$. micdade $i$ and within each serogroup there may be genotype and phenotype variations. Thus the Pontiac subgroup of L. pneumophila serogroup 1 is the one associated with most of the outbreaks reported. This would tend to indicate the presence of virulence related factors such as antigen monoclonal antibody number 2 (MAb2), macrophage infectivity potentiator (MIP) and/or other proteins, although virulence is probably a multifactorial phenomenon. 2) The inoculum to which patients were exposed. Environmental concentrations of $3,000-7,000 \mathrm{cfu} \cdot \mathrm{L}^{-1}$ would be sufficient to produce one case per year in a susceptible population [18]. Several outbreaks have observed a relationship with the inoculum. Thus two workers in a cooling tower with different levels of exposure developed pneumonia and Pontiac fever, respectively [19], while in an outbreak affecting 59 English tourists in Benidorm, the prevalence was higher among those first to use the showers, suggesting that Legionella multiplied and concentrated during the night, when not in use [20]. 3) Immunological conditions or underlying disease. However, neither had any influence in this outbreak, although both were heavy smokers.

In the patients affected by this outbreak, the most decisive factor was the failure to diagnose [21, 22], adequately treat [23] and probably, exposure to a massive inoculum while repairing the water pump, since the two mechanics affected were known to have become dirtier and wetter than the remaining three mechanics working on the pump. The fact that only L. pneumophila serogroup 1 subgroup Pontiac was isolated in the patient with a positive culture, whereas in water samples from the pump other serogroups were also found, could be explained by the higher virulence of this subgroup. Community outbreaks generally result from this subgroup, while hospital outbreaks may be due to other serogroups, since the patients would tend to be more susceptible [24]. This 
would also explain why the other serogroups detected in the ship $[4,8,10]$ had affected neither crew members nor the mechanics.

In the face of an increased prevalence of pneumonia in a given area and even in the differential diagnosis of fever, it is important to rule out legionellosis since early diagnosis is decisive in reducing the poor prognosis of this disease, as may be deduced from this paper. Both patients were considered repeatedly to have influenza, the correct diagnosis only being reached after death. In the diagnosis and treatment of pneumonia acquired in the community, recommendations based on criteria of severity should be followed, whether at the beginning or during the course of the disease [25], using macrolide antibodies in the case of empirical treatment [14].

The quickest diagnostic method is detection of the urinary antigen (sensitivity $>80 \%$, specificity $100 \%$ ) elimination of which may take several weeks or even months. Nonetheless, it should be noted that the urinary antigen test used in these cases only detects $L$. pneumophila serogroup 1 and may be negative in the early phase of the disease. Cultures using BCYE $\alpha$ media constitute the reference diagnosis technique, and when patients have not received treatment, can achieve a sensitivity of $>70 \%$ [26]. Legionella was not isolated in lung tissue samples of Patient $\mathrm{A}$, in spite of processing different fragments. The advanced stage of autolysis of the lung parenchyma might have been accompanied by alterations in bacterial viability which would explain the absence of growth. The serological demonstration of legionellosis is based on antibody seroconversion. However, seroconversion may be slow, $\geqslant 6-8$ weeks [26], and this would explain the negative result for Patient B. Furthermore, absence of seroconversion among mechanics and crew members who developed influenza-like symptoms cannot be completely ruled out.

All kinds of repairs in watery environments with aerosol production may result in legionella infection. Hence, in the repair of ships, particularly when they have been inactive, the possibility of contamination by $L$. pneumophila should be borne in mind, and preventive and control measures taken (use of masks, checking for presence of L. pneumophila, with treatment if necessary). In the UK there is legislation concerning the maintenance of water installations in ships, but international legislation is required, since ships have high mobility and undergo changes of ownership and name. Furthermore, if the ship is contaminated, eradication of $L$. pneumophila can be very difficult as was observed in this investigation. The general lines of such legislation are simple: reduce the possibility of using contaminated water by disinfecting, filtering and suitably storing the water; avoid dead spaces in the installations; clean and disinfect whirlpool spa installations; keep cold water cold, and hot water hot; periodically replace components of the installation which could favour dissemination of bacteria. The cost of not implementing these measures can be high (deaths, a negative impact on tourism, and suspension of activity of the ship and its crew for many days, as happened in this outbreak).

In the investigation of an outbreak of this type, collaboration and coordination between a variety of health-related and nonhealth-related professionals is necessary, and these may be separated geographically by large distances. In this sense, the efforts of The European Working Group for Legionella Infections [27] in recent ship-related outbreaks are deserving of a mention, communicating cases to a coordinating centre, thus permitting detection of epidemic outbreaks and initiation of corrective measures.

\begin{abstract}
Acknowledgements. The authors would like to thank M. Rodriguez, J. Vera, M. Parera (Servicio de Microbiología, Hospital Clínic, Barcelona, Spain); J.L. Valverde (Instituto Nacional de Toxicología de Barcelona, Spain); J. García de León (Servicio de Epidemiologia, Junta de Andalucía); Y. Torre and M. Repeto (Instituto Nacional de Toxicología de Sevilla, Spain).

The Legionellosis study group: V. Ausina (Servei de Microbiología Hospital Germans Trias i Pujol de Badalona); J.L. Borderías (Servicio de Neumología Hospital San Jorge de Huesca); M.A. Marcos (Servei de Microbiologia IDIBAPS, Hospital Clinic, Barcelona, Spain); J. Masdeu (Servei d'Anàlisi I Vigilància Ambiental, Ajuntament de Barcelona, Spain); J. Mensa (Servei de Malalties Infeccioses, Hospital Clinic de Barcelona, Barcelona, Spain); X. Mir (Servei d'Epidemiologia, Institut Municipal de Salut Pública, Barcelona, Spain); M. Solé (Servei d'Anatomia Patològica, Hospital Clinic de Barcelona, Barcelona, Spain); A. Torres (Servei de Neumología Hospital Clínic de Barcelona, Barcelona, Spain).
\end{abstract}

\section{References}

1. Garbe PL, Davis BJ, Weisfeks JS, et al. Nosocomial Legionnaires disease, epidemiologic demostration of cooling-towers as a source. JAMA 1985; 254: 521 524.

2. Benthanm RH, Broadbent CR. A model for autumn outbreaks of legionnaires disease associated with cooling-towers, linked to system operation and size. Epidemiol Infect 1993; 111: 287-295.

3. Jernigan DB, Hofmann J, Cetron MS, et al. Outbreak of Legionnaires' disease among ship passengers exposed to a contaminated whirpool spa. Lancet 1996; 354: 494-499.

4. Hanrahan JP, Dale LM, SchBf VB, et al. A community outbreak of legionellosis: transmission by potable hot water. Am J Epidemiol 1987; 125: 639-649.

5. Redd SC, Lin FY, Fields BS, et al. A rural outbreak of Legionnaires disease linked to visiting a retail store. Am J Public Health 1990; 80: 431 - 434.

6. Plouffe JF, File TM, Breiman RF, et al. Reevaluation of the definition of legionnaires' disease: use of the urinary antigen assay. CID 1995; 20: 1286-1291.

7. Pelaz C, García L, Martín BC. Legionellae isolated from clinical and environmental samples in Spain (1983-1990): monoclonal typing of Legionella pneumophila serogrup 1 isolates. Epidemiol Infect 1992; 108: $397-402$.

8. Valsangiacomo C, Baggi F, Gaia V, Balmelli T, 
Peduzzi R, Piffaretti JC. Use of amplified fragment length polymorphism in molecular typing of Legionella pneumophila and application to epidemiological studies. J Clin Microbiol 1995; 33: 1716-1719.

9. Fry NK, Alexiou-Daniel S, Bansborg JM, et al. A multicenter evaluation of genotypic methods for the epidemiologic typing of Legionella pneumophila serogroup 1: results of a pan European study. Clin Microbiol Infec 1999; 5: 462-477.

10. Fiore AE, Pekka NJ, Levine OS, et al. Epidemic Legionnaires' disease two decades later: old sources, new diagnostic methods. CID 1998; 26: 426-433.

11. Ledesma E, Camaro ML, Carbonell E, et al. Subtyping of Legionella pneumophila isolates by arbitrarily primed polymerase chain reaction. Can J Microbiol 1995; 41: 846-848.

12. Caylà JA, Sala MR, Plasencia A, et al. Brote comunitario de enfermedad de los legionarios en Barcelona: investigación epidemiológica y medioambiental. Med Clin (Barc) 1989; 93: 526-530.

13. Ciscar MA, Barranco MJ, Peris R, Ramon M, Juan G. Brote de enfermedad del legionario en una comunidad abierta: 10 años después. Enferm Infec Microbiol Clin 1994; 12: 325-331.

14. Blanquer J. Los brotes de Legionelosis en España. Arch Bronconeumol 1997; 33: 431 - 433.

15. BES. Informe del brote de neumonía por Legionella de Alcalá de Henares, Madrid (abril 1997 I y II). Bol Epidemiol Sem 1991; 15: 133 - 152.

16. Rowbotham TJ. Legionellosis associated with ships: 1977 to 1997. Commun Dis Public Health 1998; 1: $146-151$.

17. CDC. Update: Outbreak of Legionnaires' Disease Associated with a Cruise Ship, 1994. MMWR 1994; 43: $574-575$.

18. Ezzeddine H, Van Ossel C, Delmee M, Wauters C.
Legionella spp in a hospital hot water system: effect of control measures. J Hosp Infect 1989; 13: 121-131.

19. Girod JC, Reichman RC, Winn WC Jr, Klauche DN, Vogt RL, Dolin R. Pneumonic and nonpneumonic forms of Legionellosis. The result of a common source exposure to Legionella pneumophila. Arch Intern Med 1982; 142: $545-547$.

20. Reid D, Grist NR, Najera R. Illness associated with "package tours" a combined spanish-scottish study. Bull WHO 1978; 56: 117-122.

21. Respiratory complications. In: Nicholson KG, ed. Managing influenza in Primary Care. London, Blackwell Science, 1999; pp. 38-40.

22. American Thoracic Society. Guidelines for the initial management of adults with community-acquired pneumonia: diagnosis, assesment of severity, and initial antimicrobial therapy. Am Rev Respir Dis 1993; 148: $1418-1426$.

23. El-Ebiary M, Sarmiento X, Torres A, et al. Prognostic factors of severe Legionella pneumonia requiring admission to ICU. Am J Respir Crit Care Med 1997; 156: $1467-1472$.

24. Pelaz C, Martin-Bourgon C. Caracterización de los aislamientos clínicos y ambientales de Legionella asociados con brotes y estudio de las fuentes de infección. Enferm Infec Microbiol Clin 1993; 7: 359-365.

25. Dorca J, Bello S, Blanquer J, et al. Diagnóstico y tratamiento de la neumonía adquirida en la comunidad. Normativa SEPAR. Arch Bronconeumol 1997; 33 : $240-246$.

26. González J, Celis MR. Diagnóstico de las infecciones respiratorias en la comunidad. Med Clin (Barc) 2000; 14: Suppl., 1-5.

27. Hutchinson EJ, Joseph C, Bartlett CLR. EWGLI: A European Surveillance Scheme for travel associated legionnaires' disease. Eurosurveillance 1996; 1: $37-39$. 